\title{
Higher Education As A Pathway To Entrepreneurship
}

\author{
Mohamed Imam Salem, King Saud University, Kingdom of Saudi Arabia
}

\begin{abstract}
The driving force of every successful economy in the world is entrepreneurship. Entrepreneurial university is a concept which explains universities that provide a good environment, culture, opportunities, and practices that enhance student entrepreneurship. This study discusses components that characterize the entrepreneurial university such as leadership and governance, organizational capacity, people and incentives, entrepreneurship development in learning and teaching, university relationship for exchange of knowledge, and entrepreneurial university as an international institution. The study confirms the critical role that higher education institutions play in fostering entrepreneurial culture among university students and staff.
\end{abstract}

Keywords: Entrepreneurship; Higher Education; Entrepreneurial University

\section{INTRODUCTION}

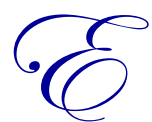

ntrepreneurial University is a concept that draws a lot of debate among scholars. It defines universities that provide environments, cultures, practices, and opportunities that are conducive to encourage and embrace graduate and student entrepreneurship. These are places where entrepreneurship is integrated into the policy and institutional arrangements of the education system. The convergence of demographic trends, knowledge-based economies and technological innovation has increased focus on the importance and effects of entrepreneurship. Entrepreneurship is, therefore, a driving force for job creation, structural changes, and economic development. In addition, it provides an avenue to address issues of poverty in the society (Gibb, Haskins, \& Robertson, 2013).

Low cost transport, rapid development, and globalization have changed the nature of work (Gibb, Haskins, $\&$ Robertson, 2013). Learners, who are the essential components of the future workforce, have a big role in dealing with the complexity and uncertainty presented by the future. Their efforts are meant to deepen technical, structural, social, and economic changes. Indicators of societal changes are increased aging population and environmental sustainability, increasing number of emerging economies, and a shift to knowledge-based and service economies. In addition, the rapid growth in social networks illustrates how the boundaries have failed to be defined by physical measures. This implies that the creation of new conditions of work requires novel responses. Institutions of higher education face many challenges, preparing the students to work in a global environment that is entrepreneurial, rapidly changing, and dynamic. In this context, there are opportunities for increased entrepreneurship in higher education.

Entrepreneurship is important in higher education. It protects intellectual property by enhancing its commercial capacity to make it accessible to a broad population. In addition, it provides a platform for scholarship which promotes integration and relevance, therefore creating the impetus for partnership with other stakeholders. This partnership strengthens the focus of higher education on development through research rather than publication. As a result, it promotes interdisciplinary teaching and research. Entrepreneurship provides an avenue through which regional, social, and economic development is established. Regional integration links higher education with many stakeholders in the society. Therefore, they strengthen development (Gibb, Haskins, \& Robertson, 2013).

Entrepreneurship has different benefits to students. It is the process through which students are equipped for the real world that has many complexities, uncertainties, and opportunities. The world, to which students are 
prepared for, is characterized by changing status in contracts, jobs, and occupation. In addition, the world is experiencing complex global mobility that new entrants require innovative and creative skills to handle different challenges represented by this global system (Naguib, 2013). Furthermore, due to fluidity in the organizational culture, the new order requires a dynamic person that can adapt to these changes. Entrepreneurship equips students with skills necessary to fit in this dynamic environment. However, as the country experiences financial and employment problems, there is a need to generate a population that will create new employment opportunities rather than relying on already established opportunities. Students exist in social units that require skills to meet their social needs. Entrepreneurship provides knowledge that develops responsible people in the social and family life. Therefore, entrepreneurship prepares the student for a life-long learning process (Gibb, Haskins, \& Robertson, 2013).

The Introduction illustrates the benefit of this concept and its practice to students, institutions, and the community. Subsequent sections explore how leadership and governance of an institution promotes entrepreneurship; discuss how organizational capacity, people and incentives can limit or promote this practice; explain how entrepreneurship can be integrated into learning and teaching; discuss the key requirements for a university to qualify as a pathway for entrepreneurs; explain that internal and external partnerships are a necessity for entrepreneurship; mention how internationalization influences an entrepreneurial university; and conclude the study.

\section{Leadership and Governance}

Entrepreneurship is determined by the governance and leadership of universities (O'Connor, 2012). For the development of entrepreneurial culture in an institution, there should be good governance and strong leadership. Inclusion of the word "enterprise" in the mission of universities should be more than a reference. There are various factors that an institution has to consider that strengthen its entrepreneurial agenda.

First, entrepreneurship should be incorporated in the strategy of an institution. This means that these institutions should consider themselves as entrepreneurial entities. Therefore, their environment should be held together by a common mission. Entrepreneurial culture and activities should be established within the strategy. In addition, these institutions have missions that have entrepreneurial vision. This may be done by stating specific entrepreneurial objectives with performance indicators. The leadership should commit to implement the entrepreneurial strategy. Raising awareness among students and staff on the priority of the strategy facilitates achievement of this mission. Furthermore, this should be supported by strong internal communication. Regular updates to the strategy ensure that it conforms to the changing international system (O'Connor, 2012).

Secondly, institutions should develop a model that integrates entrepreneurial activities in all units (O'Connor, 2012). There are various models for integration of entrepreneurial activities. However, the choice of the model should maximize the relationships that exist within these institutions. These models are useful because they avoid duplication of work in the university and the local entrepreneurial ecosystem; in addition, various departments should operate in autonomy. This is useful because it overcomes bureaucratic barriers to entrepreneurship and speeds up creative and innovative ideas where new centers for development can be established easily. Therefore, these institutions should maximize on individual ownership of the initiative and autonomy. Furthermore, institutions of higher education are the key factors in promoting entrepreneurship development in the entire community, social and regional environment. Therefore, these institutions should take an active role in development and increase presence in the community.

\section{Organizational Capacity, People, and Incentives}

Organizational structures and approaches can limit the ability of higher institutions of education to achieve their goal, which promotes entrepreneurial activities. However, there are key areas that any institution can consider in minimizing these limitations. These include providing incentive for entrepreneurial behaviors, attracting and retaining the right personalities, and developing sound financial strategy (O'Connor, 2012). 
A sustainable financial strategy should be developed to invest in entrepreneurial activities. However, it should not over-rely on limited public resources. Universities are said to be entrepreneurial when they are not afraid to use their abilities maximally, reduce dependency on public funds, and diversify their resources. Sustainable plans, especially financial strategy, define entrepreneurial institutions. Such plans should sustain ideas from development to execution. In addition, an entrepreneurial university can break through traditional boundaries to promote new relationships. These relationships are meant to develop a partnership among different stakeholders (students and staff); they also initiate synergy among the stakeholders. These are internal stakeholders who provide required capacity in supporting an entrepreneurial agenda. However, this partnership should be extended to external stakeholders to exploit both internal and external capacities for the achievement of entrepreneurial objectives (O'Connor, 2012).

In addition, entrepreneurial universities recruit and retain people with entrepreneurial experience, behaviors, and attitudes which foster an entrepreneurial culture in the universities (O'Connor, 2012). However, this should not be limited to internal staff alone. Considering external viewpoints give the institutions an external perspective which stimulates internal stakeholders. Staff development is another aspect which promotes entrepreneurial culture because the staffs are the crucial players in the fulfillment of the organizational strategy. However, entrepreneurship is an activity that strives to adapt to the changing nature of the human environment. Therefore, there is a need to ensure that human capacity reflects these changes by providing constant staff trainings.

Furthermore, universities should institute a system of providing incentives to members who take part in implementing an entrepreneurial agenda, which enhances the entrepreneurial culture in the institution. However, entrepreneurial behaviors are reinforced by rewarding and encouraging entrepreneurial initiatives, which may include providing laboratory space for those who wish to pursue entrepreneurial activities. Finally, an entrepreneurial university gives recognition and status to other stakeholders who contribute to the entrepreneurial agenda of the university. This means that external stakeholders should be valued because they bring opportunities, knowledge, and skills required for development. Various opportunities and activities are used to recognize the value of external stakeholders, which include offering them services and facilities, fellowship opportunities, giving industrial professors an opportunity to teach as guest teachers, associateship, and rewarding them for engaging in entrepreneurial activities (O'Connor, 2012).

\section{Entrepreneurship Development in Learning and Teaching}

The role of universities in the global economy is rapidly increasing (O'Connor, 2012). Entrepreneurial education offered in universities has increased the pace of globalization. However, this is achieved through a definitive framework that facilitates entrepreneurial development. Entrepreneurial university has special structures that facilitate entrepreneurial development in all activities. This means that universities create departments that manage entrepreneurial activities within the institution. These structures are supported by external funds and platforms for exchange of ideas between the external and internal stakeholders. There are different approaches used in universities to stimulate entrepreneurial learning. Rather than delivering skills through traditional lectures, various approaches are used to produce the desired outcomes where different topics use varied approaches. In addition, students respond differently to different strategies. Entrepreneurial university enhances the ability of students to think and respond creatively. These approaches include cross-disciplinary learning, living labs and the use of mentors, among others. In addition, students can also start up their companies, initiate competition and awards, run entrepreneurship clubs, and become ambassadors of their entrepreneurial initiatives.

A university supports entrepreneurial behaviors through awareness creation and stimulation of ideas from development and execution. Entrepreneurial behaviors are supported through extracurricular activities and teaching. Entrepreneurship education is also delivered by real entrepreneurs using various methods like real experience, games and stimulation, and case studies. This is also done through formal and informal learning. In addition, entrepreneurial universities validate outcomes of entrepreneurship learning by regular reviewing and updating of the course content of entrepreneurial studies. Furthermore, expected outcomes are codified in relation to competence, skills, and knowledge in all programs. Learning outcomes are validated at the institutional level. This is done using appropriate mechanisms such as internal and external moderators (O'Connor, 2012). 
Engaging and collaborating with external stakeholders is a significant component of learning and teaching in an entrepreneurial university. However, various universities do not recognize the importance of external stakeholders such as the local government, local organizations, and communities (Audretsch, 2012). This collaboration can generate a new relationship that acts as a source for new expertise and experience to be used in entrepreneurial education. It also offers updated information to entrepreneurial universities. Finally, research results are integrated into entrepreneurial training and education. Integrating the results of research into learning and teaching is useful because it updates the content of programs. However, this should be done using the current and relevant research results (O'Connor, 2012).

\section{University as a Pathway to Entrepreneurs}

The decision to be entrepreneurial is a process. For institutions of higher education to be entrepreneurial, they should facilitate those who aspire to be entrepreneurs including staff and students (Byrnes, Paez, Blacker, Jackson, \& Dwyer, 2010). This process includes both the internal and external stakeholders through pluralistic approach which is useful because it provides avenues to exploit both internal and external expertise and opportunities. It is achieved when universities raise awareness of the importance or value of generating entrepreneurial abilities among students and staff. This implies that universities provide opportunities and facilities to act on ideas developed by students and staff. Therefore, developing awareness of the value of having entrepreneurial ability is an essential function of these institutions which includes abilities that support development of new ideas, career development, and employability.

In addition, this process demands that universities encourage entrepreneurial behaviors. Therefore, universities highlight the importance of developing new ideas and opportunities, followed by encouraging them to take up these opportunities. Entrepreneurial universities encourage students and staff to develop skills, behaviors, and a mindset that are entrepreneurial at an individual level. Nevertheless, it is the role of the university to provide platforms upon which students and staff experience entrepreneurship which is done once they have understood the importance of entrepreneurship and developed an entrepreneurial mindset. It may include provision of exposure to both students and staff and will expose them to different challenges that encourage them to develop entrepreneurial skills. It includes exposing them to real life problems, allowing them to interact with entrepreneurs and trainings, and may also include integration of enterprise activities in education strategies. This prepares students for the real world of entrepreneurship by translating what they learn into practice (Byrnes, Paez, Blacker, Jackson, \& Dwyer, 2010).

Furthermore, entrepreneurial universities assist the students and staff to move entrepreneurial ideas into action which means that developing this idea is a single step (Byrnes, Paez, Blacker, Jackson, \& Dwyer, 2010). Therefore, universities should provide opportunities and services to act on these ideas, meaning that the universities assist students from creation to the implementation of the idea. In addition, universities should link students with the external ecosystem of entrepreneurship. Institutions of higher learning should provide both industrial and academic mentorship. Mentorship is an efficient learning process used as a support tool to reinforce entrepreneurial skills acquired by students, and matching students with appropriate entrepreneurs will increase chances of developing adaptive entrepreneurial skills required in the dynamic environment. Mentoring services should be provided to both graduates and students through alumni and other external stakeholders.

Universities help potential entrepreneurs to access private financial services, which is useful because it helps universities in creating a link with relevant industries. To accomplish this, universities provide networking activities for new entrepreneurs. In these events, potential entrepreneurs meet investors who help them pitch their ideas. Furthermore, institutions help students to access private financial opportunities. Finally, universities act as incubation facilities to students and staff with entrepreneurial ideas; therefore, they are used to start the entrepreneurial ideas and create a link to the industries. This includes provision of training, access to financing, mentoring, coaching, IT services, research facilities, laboratories, and subsidized premises (Byrnes, Paez, Blacker, Jackson, \& Dwyer, 2010). 


\section{University Relationship for Exchange Knowledge}

Active involvement of various stakeholders is useful for successful entrepreneurial universities (Byrnes, Paez, Blacker, Jackson, \& Dwyer, 2010). This requires building and sustaining links with collaborators and partners in achieving the full potential of a university. This relationship is established among different components of the society, including professional bodies, alumni, businesses, regions, and public sectors. The idea behind this collaboration is to create value for both the society and the university.

Entrepreneurial university is committed to knowledge exchange and collaboration with public sectors, society, and industry (Guerrero \& Urbano, 2012). Collaboration and partnership should be integrated into the institutional policies of a university to manage relationships with all sectors. Furthermore, these policies have support mechanisms to coordinate partnerships. However, among all sectors, the university should demonstrate an active role in partnership, which means that an entrepreneurial university takes the leading position in supporting partnership with other stakeholders. In addition, the university should be involved in a range of partnerships at local, regional, and global levels (Byrnes, Paez, Blacker, Jackson, \& Dwyer, 2010).

Second, an entrepreneurial university has a strong link with external initiatives, such as science parks and incubators, to develop opportunities for dynamic knowledge exchange. This creates added value through establishing a partnership with external environments and is done because many knowledge intensive institutions surround a university. Therefore, a university develops mechanisms to capitalize on the knowledge acquired. This mechanism facilitates cross-development of knowledge, collaboration space, organization of joint workshops, and other networking opportunities and is enhanced further when universities create opportunities for its students and staff to take part in the external environment or entrepreneurial activities. This means that universities provide opportunities for its students and staff to take part in extensive entrepreneurial activities in the external environment. Knowledge exchange mechanism developed by the university supports collaboration with the external environment. This may be done through joint curriculum development and provision of internship among others (Byrnes, Paez, Blacker, Jackson, \& Dwyer, 2010).

Third, entrepreneurial universities support students and staff mobility between the external environment and academia (Byrnes, Paez, Blacker, Jackson, \& Dwyer, 2010). Programs like research exchange and internship facilitate this mobility. In addition, entrepreneurial university provides a link to the wider community, education, and research to promote the knowledge ecosystem. Therefore, universities should have a mechanism to absorb knowledge, information, and experience created in the wider ecosystem. In teaching, this includes using strategies such as inviting guest teachers and internships. In research, contract work and collaborative partnership are used to enhance these links. However, universities should provide mechanisms to exploit entrepreneurial opportunities with industrial and commercial partners.

\section{University as an International Institution}

Entrepreneurial university is characterized by an international perspective through integrating internationalization into its strategic processes which is essential because it allows universities to make an informed decision on institutional direction and to evaluate and enhance performance based on different objectives that reflect international activities. Though it is not possible for an institution to be entrepreneurial without being international, it can be international without being entrepreneurial. This means that internationalization is a crucial component of an entrepreneurial strategy of a university and includes integration of global and intercultural dimension into delivery, functions, and purpose of education. Commitment placed on international strategy reflects entrepreneurial objectives (Gibb, Haskins, \& Robertson, 2013).

Finally, entrepreneurial university supports international mobility of the students and staff (Gibb, Haskins, \& Robertson, 2013). This is done by attracting international students and staff and supporting its local students to participate in international activities, and it may include overseas internship, scholarships, and exchange schemes. They can also use rewards and incentives to support international mobility (Guerrero \& Urbano, 2012). Recruiting entrepreneurial staff at an international level enhances an international outlook. However, recruitment should ensure it matches the needs of the university. 


\section{CONCLUSION}

Different approaches are used to define an entrepreneurial university. These definitions propose guidelines that characterize such institutions. Leadership and governance are key components that define this framework because it promotes an entrepreneurial culture. In addition, organizational capacity, incentives, and people can either be a limit or an opportunity to the efforts of a university to become entrepreneurial. However, integrating entrepreneurship development in learning and teaching should involve both staff and students. Therefore, university as a pathway for entrepreneurs involves many processes that require support from different stakeholders. This pathway requires collaboration and partnership with professional bodies, alumni, businesses, regions, and public sectors. Finally, an entrepreneurial university should reflect an international perspective in its objectives. Internationalization enhances performance of a university; therefore, higher education as a pathway to entrepreneurship involves the need to reflect an international perspective.

\section{ACKNOWLEDGEMENT}

This study is supported by the Deanship of Scientific Research at King Saud University.

\section{AUTHOR INFORMATION}

Mohamed Imam Salem is a faculty member and senior researcher at Prince Salman Entrepreneurship Institute at King Saud University in Saudi Arabia. E-mail: miisalem@ hotmail.com

\section{REFERENCES}

1. Audretsch, D. B. (2012). From the entrepreneurial university to the university for the entrepreneurial society. Journal of Technology Transfer, 35(1), 1-9. doi 10.1007/s10961-012-9288-1

2. Byrnes, J., Paez, D., Blacker, J., Jackson, A., \& Dwyer, C. (2010). The future of higher education in the knowledge-based economy: Developing innovative approaches to integrated articulation and credit transfer in Australia. Proceedings of the International Higher Education Partnerships and Innovation (IHEPI) Conference Budapest: From Higher Education to Innovation: Management and Entrepreneurship in a Changing Market, 91-101. Publikon Publishers/IDResearch Ltd.

3. Gibb, A., Haskins, G., \& Robertson, I. (2013). Leading the entrepreneurial university: Meeting the entrepreneurial development needs of higher education institutions. Universities in Change, 9-45. New York: Springer.

4. Guerrero, M., \& Urbano, D. (2012). The development of an entrepreneurial university. The Journal of Technology Transfer, 37(1), 43-74.

5. Lazzeroni, M., \& Piccaluga, A. (2003). Towards the entrepreneurial university. Local Economy, 18(1), 3848.

6. Maunter, G. (2005). The entrepreneurial university. A discursive profile of a higher education profile. Critical Discourse Studies, 2(2), 95-120.

7. Moreland N. (2007). Entrepreneurship and higher education: An employability perspective. UK: The Higher Education Academy.

8. Naguib, M. (2013). A strategic analysis of the entrepreneurial university development. European Journal of Innovation and Business, 9, 16-22.

9. O'Connor, A. (2012). A conceptual framework for entrepreneurship education policy: Meeting government and economic purposes. Journal of Business Venturing, 4(28), 546-563.

10. Volkmann, C. (2004). Entrepreneurial studies in higher education. Higher Education in Europe, 29(2), 177185 . 